\title{
Penentuan Harga Dengan Metode Back Propagation pada Aplikasi E-Commerce CariKos Berbasis Web
}

\author{
Rifqi Nur Fadhilah dan R.V.Hari Ginardi \\ Departemen Teknik Informatika, Fakultas Teknologi Informasi, Institut Teknologi Sepuluh Nopember (ITS) \\ e-mail: hari@its.ac.id
}

\begin{abstract}
Abstrak-Aplikasi CariKos merupakan aplikasi e-commerce berbasis web yang mewadahi para pencari indekos agar mudah dalam mencari indekos. Aplikasi ini menyajikan harga yang fluktuatif sesuai dengan permintaan pasar. Untuk mendapatkan harga yang fluktuatif ini digunakan metode back propagation untuk menentukan harga. Penentuan harga ini dipengaruhi oleh banyak atau sedikitnya permintaan pasar akan indekos beserta nilai skor indekos. Uji coba yang dilakukan sebanyak tiga macam uji coba, yaitu uji coba back propagation, uji coba fungsionalitas, dan uji coba tingkat kepuasan serta pengukuran keuntungan/kerugian. Uji coba metode back propagation yang digunakan untuk menentukan harga menghasilkan nilai ratarata MSE sebesar 0.030167 . Uji coba fungionalitas dan uji coba tingkat kepuasan serta pengukur keuntungan atau kerugian dilakukan oleh 5 partisipan. Uji coba fungsionalitas ini dilakukan untuk mengukur keberhasilan dalam menjalani proses bisnis. Pada uji coba fungsionalitas, semua fungsionalitas dalam aplikasi berjalan dengan baik dan benar. Uji coba tingkat kepuasan serta pengukur keuntungan atau kerugian dilakukan untuk mengukur tingkat kepuasan partisipan dengan harga yang ditampilkan dan untuk mengetahui keuntungan/kerugian yang didapat. Tingkat kepuasan partisipan terhadap harga yang ditampilkan pada aplikasi sangat baik. Lima dari lima partisipan merasa puas dengan harga yang ditampilkan pada aplikasi CariKos. Aplikasi CariKos mendapatkan keuntungan dari pemesanan yang dilakukan oleh lima partisipan sebanyak tiga kali pemesanan dalam satu periode. Sehingga metode backpropagation cocok untuk melakukan penentuan harga indekos.
\end{abstract}

Kata Kunci-Back Propagation, E-Commerce, Fluktuatif, MSE , Konvensional, Teknologi Informasi.

\section{PENDAHULUAN}

CEIRING dengan perkembangan teknologi informasi di Indonesia sektor bisnis pun semakin berkembang dan selalu ada perubahan yang nyata setiap harinya. Perubahan yang terjadi merupakan strategi pengelolaan bisnis yang sudah menggunakan teknologi untuk media bisnis. Hal ini dilakukan untuk mendapatkan hasil yang lebih baik. Apalagi dengan semakin ketatnya persaingan di dunia bisnis, membuat para pelaku bisnis harus mempunyai inovasi yang baru dan meningkatkan mutu bisnisnya. Pengusaha menyadari akan pentingnya sebuah informasi yang dapat membantu dalam mengambil suatu keputusan yang penting untuk perkembangan bisnis. Dalam perkembangannya, bisnis $e$ commerce muncul untuk mengatasi segala keterbatasan yang dapat terjadi di bisnis konvensional. Bisnis e-commerce baik untuk ditekuni oleh pengusaha sebab e-commerce membuat bisnis dapat lebih efisien dan efektif dalam meningkatkan keuntungan.

Peningkatan jumlah mahasiswa yang merantau membuat permintaan indekos meningkat di daerah sekitar kampus. Ini membuat bisnis indekos dapat dipertimbangkan sebagai bisnis yang menguntungkan. Apalagi indekos merupakan kebutuhan primer bagi mahasiswa perantauan, sehingga bisnis indekos tidak akan sepi peminat dan permintaan indekos akan selalu meningkat. Ketidak seimbangannya ketersediaan indekos dengan permintaan indekos membuat persaingan antar mahasiswa untuk mendapatkan indekos sangat ketat. Hal ini menyebabkan para mahasiswa pencari indekos yang tersedia di penghujung waktu sangat sulit.

Selain kesusahan mencari lokasi, harga menjadi salah satu faktor pendukung mahasiswa untuk memilih indekos. Saat ini kebanyakan indekos menawarkan harga yang flat tidak seperti hotel yang mempunyai harga fluktuatif di waktu tertentu. Jika indekos mengimplementasikan harga seperti harga hotel dapat menarik mahasiswa.

\section{LITERATUR PENELITIAN}

\section{A. E-Commerce}

Electronic commerce (e-commerce) adalah proses pembelian, penjualan atau pertukaran produk, jasa dan informasi melalui jaringan computer. Selain teknologi jaringan www, e-commerce juga memerlukan teknologi basis data atau pangkalan data (database), surat elektronik (e-mail), dan bentuk teknologi non computer yang lain seperti halnya sistem pengiriman barang dan alat pembayaran untuk e-commerce ini.

Dalam mengimplementasikan e-commerce tersedia suatu integrase rantai nilai dari infrasturkturnya, yang terdiri dari tiga lapis. Pertama, infrastruktur sistem distribusi (flow of good). Kedua, infrastruktur pembayaran (flow of money). Dan ketiga, infrastruktur sistem informasi (flow of information) [1]. Ada tiga faktor yang dapat dicermati jika ingin membangun toko e-commerce yaitu : variability, visibility, dan velocity. E-commerce dapat dibagi menjadi beberapa jenis yang memiliki karakteristik berbeda-beda :

\section{1) Business to Business (B2B)}

Business to Business memiliki karakteristik:

- Trading partner yang sudah ada dan mempunyai hubungan lama sehingga pertukaran informasi dapat 
disusun sesuai dengan kebutuhan dan kepercayaan (trust).

- Pertukaran data berlangsung secara berulang-ulang dan berkala dengan format yang sudah disepakati.

- Pengiriman data tidak perlu menunggu permintaan dari partner-nya.

- Model yang digunakan adalah peer-to-peer, dimana processing intelligence dapat didistribusikan kepada kedua pelaku usaha.

Umumnya e-commerce jenis ini menggunakan mekanisme Electronic Data Interchange (EDI). EDI adalah proses transfer data yang terstruktur dalam format standar yang disetujui dari satu komputer ke komputer lainnya dalam bentuk elektronik. Contoh e-commerce jenis ini di Indonesia adalah www.bizzy.co.id dan www.ralali.com.

2) Business to Consumer (B2C)

Business to Consumer memiliki karakteristik sebagai berikut:

- Terbuka untuk umum.

- Pelayanan yang diberikan bersifat umum.

- Layanan yang diberikan berdasarkan permintaan konsumen.

- Menggunakan pendekatan sistem client/server dimana client (konsumen) menggunakan sistem berbasis web dan

processing (business procedure) diletakkan di sisi server.

Pada e-commerce jenis ini berkembang sangat pesat ditandai dengan lahirnya berbagai toko online di Indonesia. Toko online menggunakan web sebagai toko virtual untuk menjajakan produk dan layanan. Contoh dari e-commerce jenis ini di Indonesia adalah www.traveloka.com dan www.tiket.com.

\section{3) Consumer to Consumer $(\mathrm{C} 2 \mathrm{C})$}

E-commerce jenis ini meliputi semua transaksi elektronik barang atau jasa antar konsumen. Kebanyakan di e-commerce jenis ini menyediakan tempat bagi penjual untuk menjualkan langsung barangnya. E-commerce ini pun yang paling terkenal di Indonesia. Contoh dari e-commerce jenis ini di Indonesia adalah www.bukalapak.com dan www.tokopedia.com.

4) Consumer to Business (C2B)

E-commerce jenis ini merupakan jenis e-commerce yang menyediakan tempat bagi individu untuk menawarkan jasa atau produk mereka kepada perusahaan yang sedang mencari jasa atau produk tersebut. Contoh dari e-commerce jenis ini di Indonesia adalah www.istockphoto.com.

\section{5) Business to Administration (B2A)}

E-commerce jenis ini mencakup semua transaksi online yang dilakukan antara perusahaan dan administrasi publik. Contoh e-commerce jenis ini di Indonesia adalah www.pajak.go.id dan www.bpjs-online.com.

6) Consumer to Administration (C2A)

E-commerce jenis ini hampir mirip dengan business to Administration (B2A) tetapi yang terlibat bukan antara perusahaan dan administrasi publik melainkan antara individu dan administrasi publik. Contoh dari e-commerce jenis ini di Indonesia adalah www.pajak.go.id.

\section{B. Teori Permintaan}

Mempertimbangkan permitaan pasar terhadap barang atau jasa diperlukan ketika kita membuka bisnis baru. Penentuan harga pun menjadi persoalan yang rumit. Jika harga semakin murah maka permintaan akan semakin banyak, tetapi penawaran semakin menurun. Ini terjadi karena ingin mencari keuntungan sebesar-besarnya. Apabila harga terlalu tinggi maka pembeli mungkin akan membeli dalam jumlah sedikit, namun berbeda dengan penjual yang akan memperbanyak barang yang dijual atau diproduksi agar mendapatkan keuntungan yang besar. Harga yang tinggi juga bisa menyebabkan konsumen akan mencari produk lain sebagai pengganti barang yang harganya mahal [2].

Dalam ekonomi terdapat satu titik pertemuan antara permintaan (demand) dan penawaran (supply) dalam satuan harga dan jumlah barang. Hukum permintaan menjelaskan hubungan antara perubahan harga suatu barang dengan perubahan barang yang diminta. Hukum permintaan menyatakan bahwa antara harga dan jumlah barang yang diminta berbanding terbalik. Artinya bila harga naik akan menyebabkan jumlah barang yang diminta akan turun dan sebaliknya, dengan syarat ceteris paribus [2].

Permintaan suatu barang bisa dikatakan elastis atau inelastis didasari atau ditentukan oleh berbagai faktor yaitu [2]:

\section{Barang Mewah dan Barang Kebutuhan}

Permintaan barang-barang kebutuhan umumnya inelastis, sedangkan permintaan barang-barang mewah umumnya elastis. Karena walaupun harga barang kebutuhan mengalami peningkatan atau penurunan, jumlah yang diminta akan tetap sama atau hanya mengalami penurunan sedikit. Berbeda dengan barang mewah jika mengalami peningkatan harga, jumlah yang diminta tidak ada. Tapi jika mengalami penurunan harga jumlah yang diminta akan meningkat.

2. Ketersediaan barang Subsitusi

Apabila suatu barang memiliki barang pengganti atau barang subsitusi akan mempunyai elatisitas yang elastis, sedangkan barang tidak memiliki pengganti atau subsitusi mempunyai elastisitas yang inelastis. Sebab ketika barang itu mengalami peningkatan harga maka permintaan akan barang tersebut akan mengalami penurunan dikarenakan tersedianya barang subsitusi yang harganya lebih rendah dari barang tersebut. Berbeda dengan barang yang tidak mempunyai barang subsitusi akan mengalami penurunan permintaan yang sedikit.

\section{Definisi Pasar}

Semakin luas ruang lingkup pasarnya maka semakin inelatis barang tersebut karena tidak ada barang subsitusinya. Sebaliknya, semakin sempit ruang lingkup pasarnya maka semakin elastis barang tersebut.

4. Rentang Waktu

Apabila rentang waktu perubahan harga suatu barang lebih lama atau jangka panjang, permintaan barang tersebut akan elastis. Karena orang-orang (konsumen) mampu untuk mencari dan mensubtitusi barang tersebut dan biasa tidak menggunakan barang tersebut lagi. Namun, untuk jangka waktu yang pendek akan mengalami inelastis karena tidak adanya kesempatan bagi konsumen untuk mensubtitusi barang tersebut.

Dengan teori permintaan ini menjadi landasan untuk menganalisis harga yang wajar untuk indekos dengan mempertimbangkan permintaan akan kebutuhan indekos. Untuk menentukan sebuah harga maka dibutuhkan algoritma 
yang dapat memprediksi harga dengan mempertimbangkan beberapa pertimbangan..

\section{Back Propagation Neural Network}

Back Propagation Neural Network mempunyai kemampuan yang kuat dari interpolasi non-linear. Metode ini secara luas digunakan dalam aplikasi teknik untuk prediksi dan optimalisasi. Back Propagation Neural Network terdiri dari input layer, beberapa hidden layer dan output layer [3]. Pada Gambar 1 dapat dilihat arsitektur back propagation.

Input layer terdiri dari nilai bias, nilai permintaan, dan nilai bobot indekos. Nilai bias merupakan nilai yang konstan dan mempunyai nilai 1 . Nilai bias digunakan untuk membuat nilai output yang diinginkan menjadi lebih optimal. Dua input yaitu nilai permintaan dan nilai skor dari indekos. Nilai permintaan merupakan nilai permintaan sewa indekos pada setiap bulan. Nilai bobot indekos merupakan nilai yang dipunya dari sebuah indekos berdasarkan kriteria. Kriterianya adalah dekat dengan supermarket atau minimarket, dekat dengan tempat ibadah, luas parkiran yang dimiliki indekos, terdapatnya penjaga indekos, ketersediaan fasilitas yang ditawarkan, tidak berada di daerah banjir, tidak berada di daerah ramai, dan dekat dengan lokasi jurusan.

Terdapat 3 fase dalam pelatihan back propagation, yaitu fase maju (feed forward), fase mundur (back propagation), dan fase modifikasi bobot. Rumus untuk perhitungan bobot :

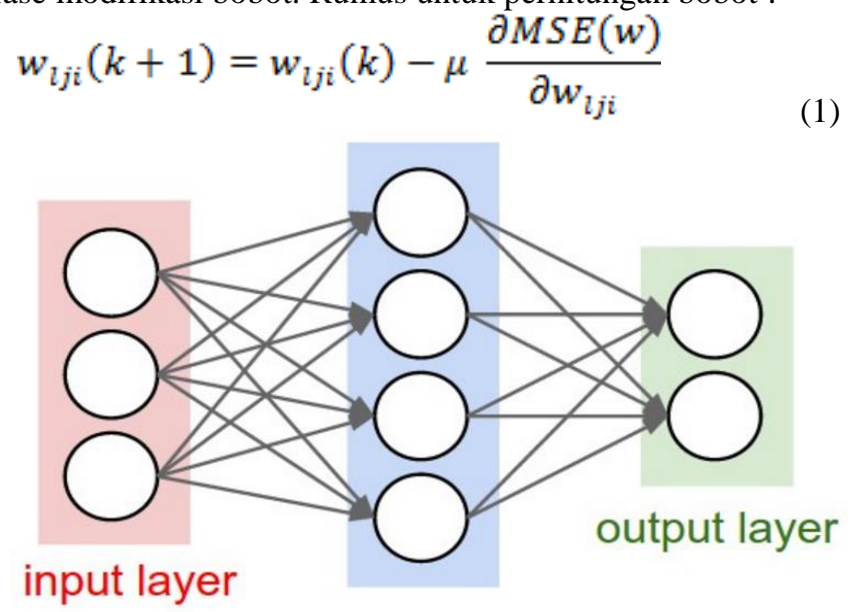

Gambar 1. Arsitektur Back Propagation

\section{hidden layer}

Dimana wlji adalah bobot antara neuron i pada layer 1-1 dan neuron j pada layer $1, \mu$ adalah bilangan real positif, learning rate yang berfungsi untuk mengontrol step pembelajaran algoritma dan biasanya diset kecil. Dalam fase back propagation, tiap-tiap unit output menerima target pola yang berhubungan dengan pola input untuk dihitung nilai kesalahan. Kesalahan tersebut akan dipropagasikan mundur. Sedangkan fase modifikasi bobot bertujuan untuk menurunkan kesalahan yang terjadi. Ketiga fase tersebut diulang secara terus menerus hingga kondisi penghentian dipenuhi.

Pada penelitian penentuan upah minimum kota berdasarkan tingkat inflasi menggunakan back propagation neural network, didapatkan nilai MSE sebesar 0.0728 [3]. Oleh sebab itu nilai MSE tersebut menjadi landasan eror minimal pada aplikasi
CariKos. Maka dari itu, untuk menentukan harga indekos dapat menggunakan back propagation neural network. Back propagation melakukan pemodelan terhadap nilai permintaan dan nilai bobot indekos untuk menentukan harga baru.

\section{PERANCANGAN DAN IMPLEMENTASI}

\section{A. Deskripsi Umum Sistem}

CariKos merupakan aplikasi berbasis web pencari indekos. Di aplikasi ini juga dapat melayani pemesanan indekos sehingga pencari tidak perlu pergi ke tempat indekos yang diinginkan. Selain itu aplikasi ini melayani juga transaksi untuk membayar pemesanan indekos. Pencarian indekos dapat disesuaikan dengan keinginan dari pencari indekos. Pencari indekos dapat memilih rentang harga sewa indekos, tipe indekos, fasilitas indekos yang diinginkan, fasilitas kamar yang diperlukan, dekat dengan jurusan yang diinginkan. Pencarian yang dapat disesuaikan ini digunakan agar indekos yang ingin dicari pencari indekos dapat sesuai kriteria yang diinginkan.

Harga yang ditampilkan di aplikasi ini tidak selalu sama disetiap bulannya. Harga naik-turun sesuai dengan permintaan di bulan itu sesuai dengan hasil kuesioner dan analisis permintaan indekos. Permintaan dapat dilihat pada Gambar 2. Selain permintaan, kualitas indekos juga menjadi dasar penentuan harga. Kualitas indekos dapat dilihat dari seberapa besar indekos mendapatkan nilai bobot.

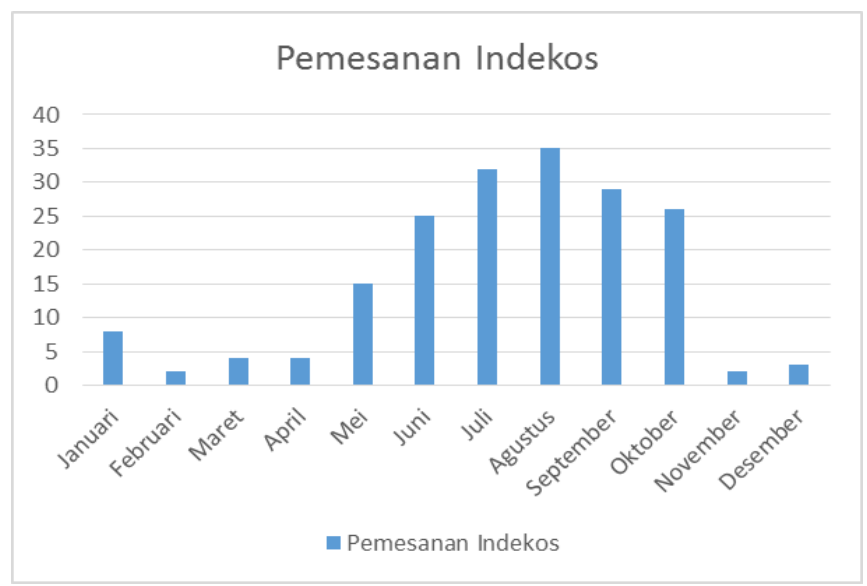

Gambar 2. Permintaan Pasar

\section{B. Penentuan Harga}

Penentuan harga didapatkan dari metode back propagation. Untuk mendapatkan harga terdapat dua proses utama pada metode back propagation yaitu, training data dan testing data. Diagram alir back propagation dapat dilihat pada Gambar 3.

\section{1) Training data}

Pada bagian ini akan dijelaskan proses data di-training hingga mendapatkan nilai MSE yang kecil. Proses training data diawali dengan melakukan normalisasi dua input terlebih dahulu. Metode normalisasi yang digunakan adalah metode min-max. Berikut ini merupakan rumus dari metode min-max: 


$$
x^{s}=\frac{0.8(x-a)}{b-a}+0.1
$$

$$
\begin{aligned}
& \text { Keterangan : } \\
& x \text { ' = hasil normalisasi } \\
& x \quad=\text { data awal } \\
& a \quad=\text { data minimal } \\
& b \quad=\text { data maksimal }
\end{aligned}
$$

Dari rumus (1) dapat dilihat bahwa data awal merupakan input sebelum dinormalisasi, data minimal merupakan nilai input yang paling kecil, dan data maksimal merupakan nilai input yang paling besar.

Setelah melakukan normalisasi data, menginisiasi weight awal antar node dengan nilai random. Nilai random tersebut memiliki rentang nilai dari -1 hingga 1 . Lalu melakukan perhitungan nilai pada hidden layer dengan menggunakan rumus berikut:

$$
z_{-} \text {net }_{j}=v_{j 0}+\sum_{i=1}^{n} x i . v j i
$$

Keterangan:

$$
\begin{array}{ll}
z_{-} \text {net } & =\text { nilai untuk menghitung hidden layer } \\
v_{j 0} & =\text { bobot bias antara } \text { input layer } \text { dengan hidden layer } \\
x i & =\text { nilai } \text { input layer } \mathrm{ke}-\mathrm{i} \\
v j i & =\text { bobot antara input layer dengan hidden layer }
\end{array}
$$

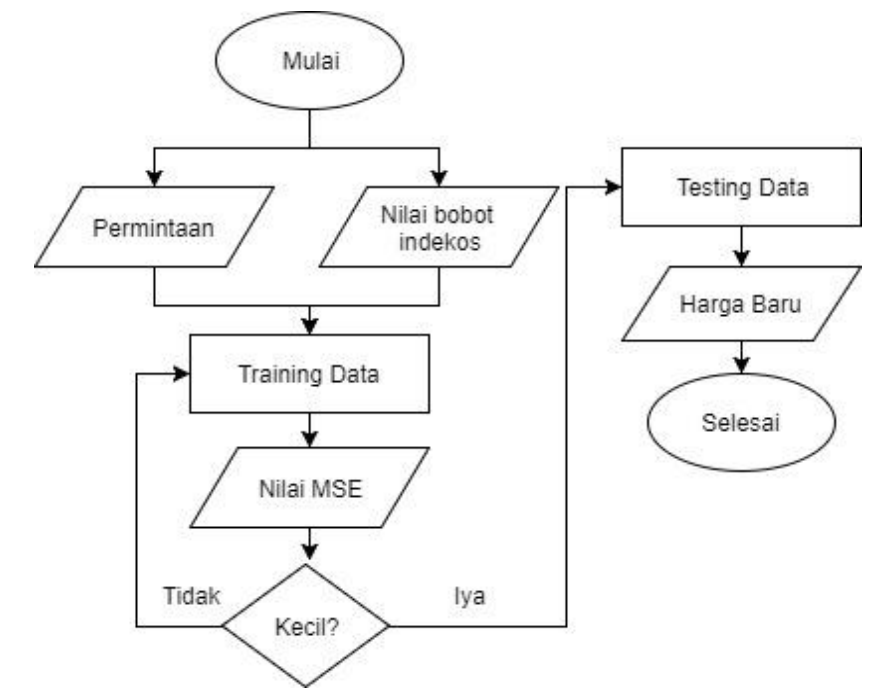

Gambar 3. Diagram Alir Penentuan Harga

Hasil dari perhitungan pada rumus (2) dilakukan aktivasi agar nilai hasilnya tetap berada di rentang nilai tertentu. Untuk melakukan aktivasi digunakan fungsi sigmoid agar rentang nilai berada di rentang 0 hingga 1 . Rumus sigmoid yang digunakan:

$$
z_{j}=f\left(z_{\text {net }_{j}}\right)=\frac{1}{1+\exp ^{\left(z_{\text {nat } \left._{j}\right)}\right)}}
$$

Keterangan:

$\begin{array}{ll}z_{j} & =\text { nilai hidden layer } \\ z_{\text {net }} & =\text { nilai untuk menghitung hidden layer }\end{array}$
Selanjutnya menghitung nilai output, yang mempunyai rumus sebagai berikut:

$$
y_{-} \text {net }_{k}=w_{k 0}+\sum_{j=1}^{p} z_{j}, w_{k j}
$$

Keterangan:

$$
\begin{array}{ll}
y_{\_} n e t_{k} & =\text { net masukan unit } \mathrm{k} \\
w_{k 0} & =\text { nilai penimbang sambungan pada bias untuk unit } \\
\mathrm{y}_{\mathrm{k}} & \\
z_{j} & =\text { nilai aktivasi dari unit } \mathrm{z}_{\mathrm{j}} \\
w_{k j j} & =\text { nilai penimbang sambungan dari } \mathrm{z}_{\mathrm{ij}} \mathrm{ke} \text { unit } \mathrm{y}_{\mathrm{k}}
\end{array}
$$

Hasil dari perhitungan rumus (4) dilakukan aktivasi agar nilainya mempunyai rentang tertentu. Maka digunakan aktivasi fungsi sigmoid agar nilai berada pada rentang 0 hingga 1 . Berikut ini rumus aktivasi fungsi sigmoid:

$$
y_{k}=f\left(y_{\text {net }}\right)=\frac{1}{1+\exp ^{\left(-y_{n a t}\right)}}
$$

Keterangan:

$$
\begin{array}{ll}
y_{k} & =\text { nilai } \text { output } \\
y_{-} \text {net }_{k} & =\text { net masukan unit } \mathrm{k}
\end{array}
$$

Setelah melakukan perhitungan dengan rumus (4) maka dilakukan perhitungan kesalahan pada setiap output dengan rumus sebagai berikut:

$$
\delta_{k}=\left(t_{k}-y_{k}\right) f^{\prime}\left(y_{n e t}\right)=\left(t_{k}-y_{k}\right) y_{k}\left(1-y_{k}\right)
$$

Keterangan:

$$
\begin{array}{ll}
\delta_{k} & =\text { nilai kesalahan pada output layer } \\
t_{k} & =\text { nilai target data } \\
y_{k} & =\text { nilai } \text { output } \\
y_{-} \text {net }_{k} & =\text { net masukan unit } \mathrm{k}
\end{array}
$$

$\delta_{k}$ merupakan nilai kesalahan yang dipakai untuk merubah bobot layer dibawahnya. Rumus yang digunakan adalah sebagai berikut:

$$
\Delta w_{k j}=\alpha \cdot \delta_{k}, z_{j}
$$

Keterangan:

$$
\begin{array}{ll}
\Delta w_{k j} & =\text { selisih antara } \mathrm{w}_{\mathrm{kj}}(\mathrm{t}) \text { dengan } \mathrm{w}_{\mathrm{kj}}(\mathrm{t}+1) \\
\alpha & =\text { nilai learning rate } \\
\delta_{k k} & =\text { nilai kesalahan output layer } \\
\mathrm{z}_{j} & =\text { nilai aktivasi dari unit } \mathrm{z}_{\mathrm{j}}
\end{array}
$$

Selanjutnya menghitung nilai kesalahan pada hidden layer berdasarkan kesalahan pada setiap hidden layer $\mathrm{z}_{\mathrm{j}}$ dengan rumus sebagai berikut:

$$
\delta_{-} \text {net }_{j}=\sum_{k=1}^{m} \delta_{k}, w_{k j}
$$

Keterangan:

$\delta_{-} n t_{j}=$ nilai untuk menghitung nilai kesalahan pada hidde layer

$\delta_{k k} \quad=$ nilai kesalahan pada output layer

$w_{k j} \quad=$ bobot dari $z_{\mathrm{ij}} \mathrm{ke} \mathrm{y}_{\mathrm{k}}$ 
Nilai kesalahan pada hidden layer dapat dihitung menggunakan rumus:

$$
\delta_{j}=\delta_{\text {net }_{j}} f^{\prime}\left(z_{-} \text {net }_{j}\right)=\delta_{\text {net }_{j} \times z_{j}}\left(1-z_{j}\right)
$$

Information:

$$
\begin{aligned}
\delta_{-} \text {net }_{j} & =\text { nilai untuk menghitung nilai kesalahan pada } \\
& \text { hidden layer } \\
z_{-} \text {net } & =\text { net masukan dari unit } \mathrm{j} \\
z_{j} & =\text { nilai aktivasi dari unit } z_{j}
\end{aligned}
$$

Setelah menghitung nilai kesalahan pada hidden layer maka dihitung perubahan bobot $\mathrm{v}_{\mathrm{ji}}$ dengan menggunakan rumus:

$$
\Delta v_{j i}=\alpha \cdot \delta_{j}, x_{i}
$$

Information:

$$
\begin{array}{ll}
\Delta v_{j \mathrm{i}} & =\text { selisih antara } \mathrm{v}_{\mathrm{ij}}(\mathrm{t}) \text { dengan } \mathrm{v}_{\mathrm{ij}}(\mathrm{t}+1) \\
\alpha & =\text { nilai learning rate } \\
\delta_{j} & =\text { nilai kesalahan pada hidden layer } \\
x_{i} & =\text { unit ke-i pada input layer }
\end{array}
$$

Terakhir melakukan update pada setiap weight. Untuk menghitung perubahan nilai weight antara hidden layer dengan output layer menggunakan rumus:

$$
w_{k j}(n e w)=w_{k j}(o l d)+\Delta w_{k j}
$$

Keterangan:

$$
\begin{array}{ll}
w_{k j j} & =\text { bobot dari } z_{\mathrm{ij}} \text { ke } \mathrm{y}_{\mathrm{k}} \text { unit } \\
\Delta w_{k j} & =\text { selisih antara } \mathrm{w}_{\mathrm{kj}}(\mathrm{t}) \text { dengan } \mathrm{w}_{\mathrm{kj}}(\mathrm{t}+1)
\end{array}
$$

Untuk menghitung perubahan nilai weight antara input layer dengan hidden layer menggunakan rumus:

$$
v_{j i}(n e w)=v_{j i}(o l d)+\Delta v_{j i}
$$

Keterangan:

$$
\begin{array}{ll}
v_{j \mathrm{i}} & =\text { bobot dari } \mathrm{x}_{\mathrm{i}} \text { unit ke } \mathrm{z}_{\mathrm{i}} \text { unit } \\
\Delta v_{\mathrm{ji}} & =\text { selisih ystem } \mathrm{v}_{\mathrm{ij}}(\mathrm{t}) \text { dengan } \mathrm{w}_{\mathrm{ij}}(\mathrm{t}+1)
\end{array}
$$

Setelah melakukan update pada setiap nilai weight maka dilakukan perhitungan nilai MSE. Mean Square Error (MSE) merupakan metode yang digunakan untuk menguji kesalahan pada system. Rumus perhitungan MSE adalah sebagai berikut:

$$
\text { MSE }=\frac{1}{k} \sum_{k=1}^{n}\left(y_{k}-t_{k}\right)^{2}
$$

Keterangan:

$$
\begin{array}{ll}
n & =\text { jumlah data } \\
y_{k} & =\text { nilai output data } \\
t_{k} & =\text { nilai target data }
\end{array}
$$

Training data dilakukan terus menerus hingga mendapatkan nilai MSE dibawah 0.0728. Jika nilai MSE sudah dibawah 0.0728 maka dilakukan testing data untuk mendapatkan harga baru.

\section{2) Testing Data}

Setelah training data sudah selesai, maka dilakukan testing data agar mendapat harga yang baru. Testing data dilakukan dengan proses perhitungan rumus (1) hingga rumus (5) pada training data. Nilai output yang didapatkan dilakukan denormalisasi terlebih dahulu dengan menggunakan metode min-max agar menghasilkan harga baru. Rumus denormalisasi metode min-max adalah sebagai berikut:

$$
x=\frac{\left(x^{*}-0.1\right)(x \max -x \min )}{0.8}+x \min
$$

Keterangan :

$\begin{array}{ll}x & =\text { data asli } \\ x & =\text { data normalisasi } \\ x \operatorname{xmax} & =\text { data maksimum asli } \\ x \min & =\text { data minimum asli }\end{array}$

Nilai maksimum diambil dari harga awal ditambah lima persen dari harga asli, sedangkan nilai minimum diambil dari harga awal dikurangi dua setengah persen dari harga awal. Hasil dari denormalisasi akan menghasilkan harga yang digunakan pada aplikasi CariKos. Penentuan harga ini diharapkan membuat harga yang fluktuatif seperti harga sewa hotel yang berbeda setiap bulannya sesuai dengan permintaan dari pasar

\section{UJI COBA DAN EVALUASI}

Pada bagian ini, akan dilakukan uji coba penentuan harga menggunakan metode back propagation dengan mempertimbangkan permintaan dan nilai bobot indekos. Gambar 5.7 merupakan harga awal dari kamar indekos, Gambar 5.8 merupakan penentuan harga jika permintaan sedang rendah, dan Gambar 5.9 merupakan penentuan harga jika permintaan sedang tinggi. Untuk itu dipilih bulan Februari sebagai bulan yang memiliki permintaan rendah dan bulan Agustus sebagai bulan yang memiliki permintaan yang banyak. Daftar permintaan dapat dilihat pada Gambar 2.

\section{Daftar Kamar Kos Trompet}

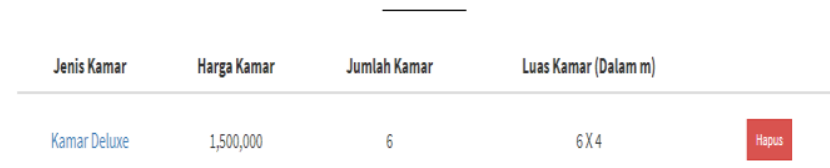

Gambar 4. Harga Awal 


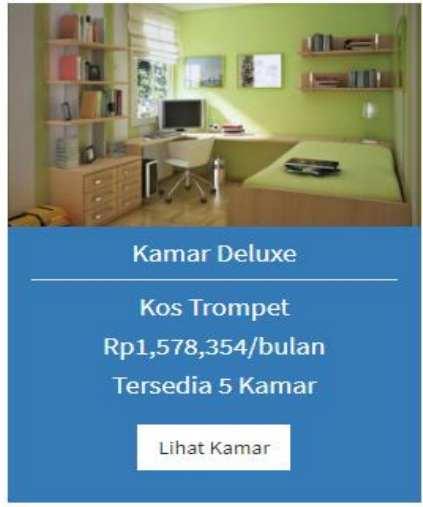

Gambar 5. Harga Akhir Ketika Permintaan Banyak

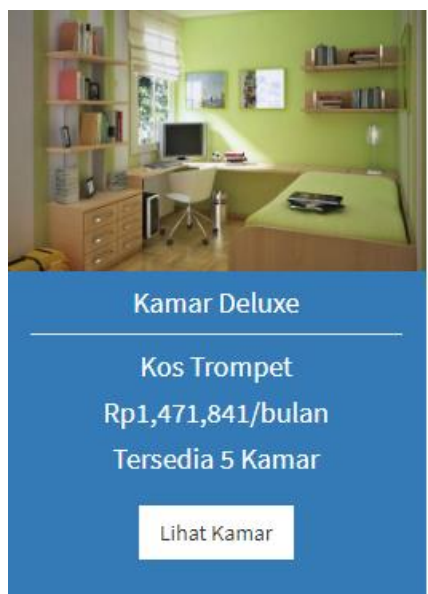

Gambar 6. Harga Akhir Ketika Permintaan Rendah

\section{KESIMPULAN}

Dari hasil uji coba penentuan harga, bahwa harga ketika permintaan tinggi mengalami kenaikan dan ketika permintaan rendah harga mengalami penurunan. Penentuan harga dilakukan dengan menggunakan metode back propagation. Hasil itu didapatkan dengan melakukan training data terhadap kedua nilai input. Training data yang dilakukan dengan iterasi sebanyak 180 kali, hidden layer berjumlah tiga, nilai learning rate yang dipakai 0.9 , dan menghasilkan nilai MSE sebesar 0.030167 .

\section{DAFTAR PUSTAKA}

[1] D. Irmawati, "Pemanfaatan E-Commers Dalam Dunia Bisnis," $J$. Ilm. Orasi Bisnis, vol. 6, pp. 95-112, 2011.

[2] E. Christianto, "Faktor yang mempengaruhi volume impor beras di Indonesia," J. JIBEKA, vol. 7, pp. 38-43, 2013.

[3] dan A. R. E. Yohannes, W. F. Mahmudy, "Penentuan Upah Minimum Kota Berdasarkan Tingkat Inflasi Menggunakan Backpropagation Neural Network (BPNN)," J. Teknol. Inf. Dan Ilmu Котри, vol. 2, no. 1, pp. 34-40, 2015. 